Cómo citar este trabajo: López Lara, E. J. (2020). Perception of the urban space of Tangier in the Spanish novels of the 21st century. Boletín de la Asociación de Geógrafos Españoles, 85, 2836, 1-26. https://doi.org/10.21138/bage.2836

\title{
Percepción del espacio urbano de Tánger en las novelas españolas del siglo XXI
}

Perception of the urban space of Tangier in the Spanish novels of the 21st century

\author{
Enrique Javier López Lara \\ elopezl@us.es \\ Departamento de Geografía Física y Análisis Geográfico Regional \\ Universidad de Sevilla (España)
}

\section{Resumen}

El artículo presenta un análisis de la percepción del espacio urbano de Tánger que la literatura española contemporánea proyecta en las dos primeras décadas del siglo XXI. La ciudad norteafricana, en los últimos 20 años, ejerce una fuerte atracción como escenario de novelas por diversas causas entre las que cabe destacar su condición geoestratégica (fronteriza, portuaria, encrucijada), su historia (en especial, época del Estatuto Internacional), sus valores económicocomerciales (Zonas Francas, Puerto Tánger-Med) y las condicionantes socio-culturales (puerta de la inmigración africana, convivencia de culturas). El estudio cuyo método reside en la detección y ordenación de los elementos geográficos percibidos en el espacio urbano en las novelas españolas del siglo XXI ha dado lugar a la elaboración de mapas de percepción: de puntos (nodos e hitos), de líneas (sendas) y de áreas (barrios y bordes). La percepción literaria del escenario urbano describe una realidad asociada a elementos característicos y emblemáticos.

Palabras clave: Tánger; literatura; percepción geográfica; siglo XXI. 


\begin{abstract}
The article presents an analysis of the perception of Tangier's urban space that contemporary Spanish literature projects in the first two decades of the 21 st century. The North African city, in the last 20 years, exerts a strong attraction as a stage for novels for various reasons, including its geostrategic condition (border, port, crossroads), its history (especially, time of the International Statute), its economic-commercial values (Free Zones, Port Tangier-Med) and socio-cultural conditions (door of African immigration, coexistence of cultures). The study whose method lies in the detection and priority of the geographical elements perceived in the urban space in the Spanish novels of the 21st century has led to the elaboration of perception maps: of points (nodes and milestones), of lines (paths) and of areas (neighborhoods and borders). The literary perception of the urban scene describes a reality associated with characteristic and emblematic elements.
\end{abstract}

Keywords: Tangier; literature; geographical perception; 21st century.

\title{
1 Introducción: percepción, literatura y geografía
}

La percepción de un espacio geográfico no es única, sino múltiple. Tantas percepciones tendrá un espacio como personas tengan posibilidad de conocerlo. La detección y ordenación de determinados elementos percibidos permite la realización de mapas de lo percibido que poseen un carácter simbólico. Mapas cuyo producto obedece a motivaciones de diversa índole que convierten en claves los elementos percibidos de cara a diagnosticar, estructurar y comprender el espacio considerado.

La literatura se muestra como fuente de información y de conocimiento geográfico interesante. Las relaciones geografía-literatura han ido confluyendo y enriqueciéndose mutuamente con el paso del tiempo. Una actualización documentada, teórica y práctica, reflexiva y fecunda de estas relaciones geografía-literatura la realiza Catalá Marticella (2017), quien afirma "(...) la validez esencial de la escritura, entendida tanto en su dimensión descriptiva como narrativa, como herramienta al servicio del conocimiento geográfico y de su transmisión" (p. XIX).

Las aportaciones de la literatura y de la geografía enriquecen a ambas disciplinas, al poseer ventajas que derivan de la tradición literaria y filosófica de la geografía (Lévy, 2006), de las confluencias entre un arte y una ciencia (Tuan, 1978; Moretti, 2000; Desbois, 2002), de la relación fenomenológica del sentimiento de arraigo entre el sujeto y los lugares (Pocock, 1988). La lectura de textos literarios es fuente de conocimiento geográfico (Suárez Japón, 2002; Boira 
Maiques, 2010), donde este, al ser ofrecido desde la ficción o la sensibilidad creativa y no desde la intencionalidad (Valle Buenestado, 2015), resulta de alto valor e interés.

En el artículo se realiza una aportación de la percepción del espacio urbano de Tánger que proyectan las novelas españolas publicadas en las dos primeras décadas del siglo XXI. Tánger ofrece un marco geográfico especial ya que su posición resulta estratégica, entre dos mares y dos continentes, y su emplazamiento particular, al elevarse la ciudad sobre una colina que domina una bahía que ejerce de puerta de entrada a la Península Tingitana, entre Cabo Espartel, al oeste y Cabo Malabata, al este. Posición y emplazamiento tuvieron relevancia en su fundación fenicia y a lo largo de la historia, siendo elementos de atracción de distintos pueblos. Además, han condicionado su urbanismo, ubicando la medina en la colina que domina la entrada del puerto, expandiéndose la ciudad europea y contemporánea en distintas etapas hacia la playa al sureste y hacia el interior, en dirección oeste - noroeste.

La percepción del espacio urbano que la literatura ofrece no se encuentra aislada, encorsetada en torre de marfil. Antes al contrario, aparece relacionada tanto con el propio escenario urbano como con otros aspectos históricos y culturales. Las confluencias de la geografía con la literatura posee numerosos caminos en función de los caracteres culturales, de los ámbitos paisajísticos y del contexto social que contribuyen a hacer más intensas las vivencias de cada persona (Catalá Marticella, 2017). En el caso de Tánger, es interesante el análisis de estas relaciones ya que están especialmente relacionadas.

Existe una relación entre la situación y el emplazamiento geográficos con los acontecimientos históricos, la cultura y la propia producción literaria (Figura 1). La encrucijada que supone la ubicación de Tánger en el flanco sur del Estrecho de Gibraltar ha sido palanca de otras derivas y condicionamientos, tanto históricos --primer emplazamiento de la diplomacia marroquí en el siglo XIX, escisión como territorio diferenciado con la puesta en escena del Estatuto Internacional, paso obligado de flujos de todo tipo entre Norte y Sur, entre Europa y África--, siendo espacio de relación y contacto a la vez que de separación y confrontación.

Por ejemplo, las relaciones socio-culturales quedan reflejadas en la conformación de un urbanismo híbrido y en la construcción de edificios singulares, con manifestaciones de tres culturas diferentes, que han dejado un notable patrimonio material e inmaterial, además de peculiares manifestaciones artísticas en la literatura, el cine, la pintura, etc. (VV.AA., 2016).

De tal manera que un espacio geográfico, sin llegar a determinismos ya superados, ha posibilitado un desarrollo histórico singular. Es de especial reseña la etapa en la que Tánger 
estuvo tutelada bajo un régimen especial, Ilamado Estatuto Internacional (1923-1956), por potencias occidentales en enfrentamiento expansionista, con diversos intereses económicos y estratégicos, que ha derivado en unas manifestaciones culturales diferenciadas que ha potenciado el propio espacio geográfico. Tánger, para la comunidad internacional allí instalada en época del Estatuto Internacional, representó una ciudad con libertades que dio lugar a la inspiración artística y, seguidamente, se convirtió en objeto de creación (Sagnes-Alem, 2007).

Figura 1. Interrelaciones Geografía-Historia-Cultura- Literatura en Tánger

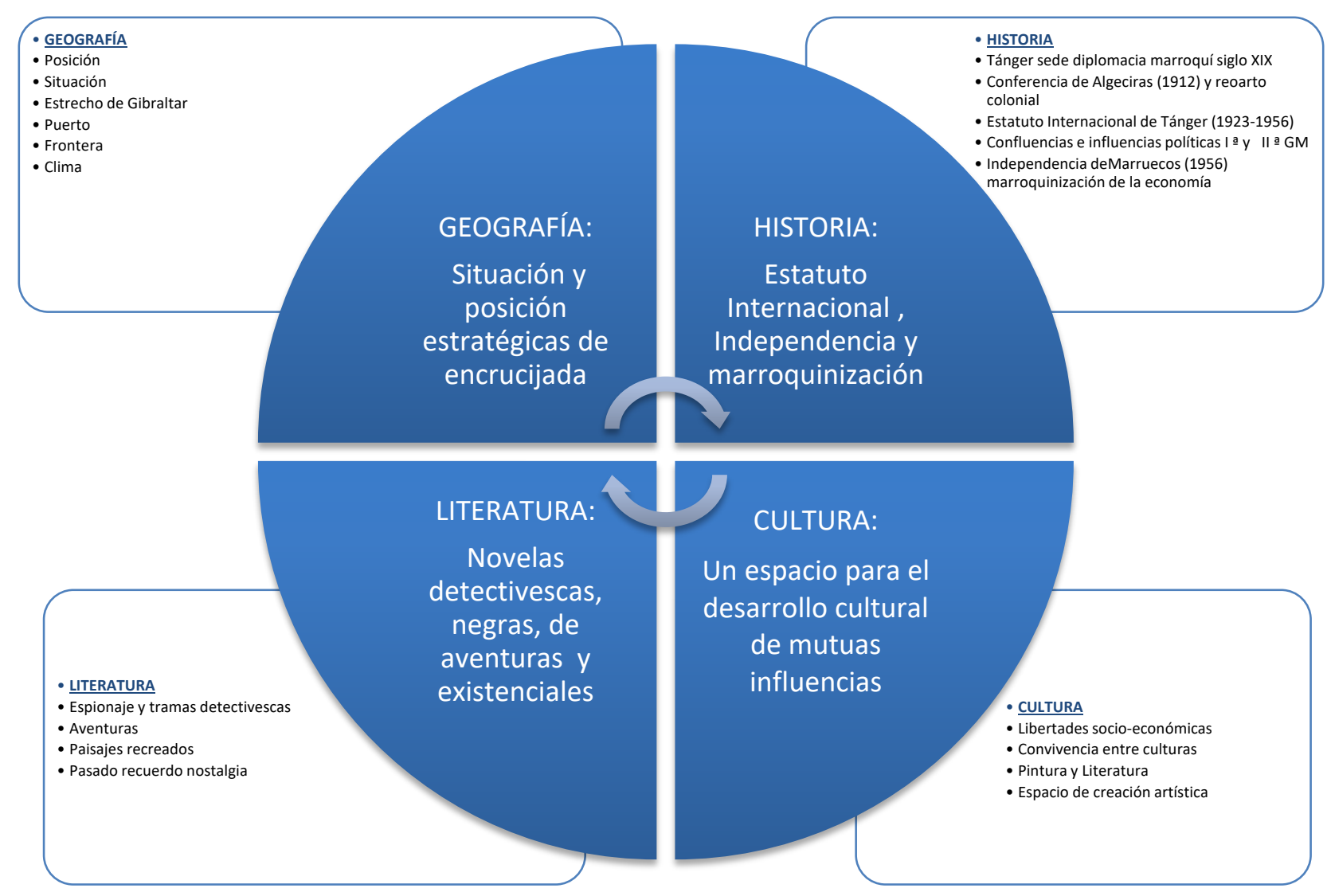

Fuente: elaboración propia

En este artículo, tras la introducción, se exponen en un segundo apartado la metodología y las fuentes utilizadas. Posteriormente, en el tercer apartado se analizan los elementos percibidos en el espacio urbano de Tánger en las novelas españolas del siglo XXI (2002-2019), elaborándose mapas de percepción de las sendas (grafos), de los hitos y nodos (puntos) y de los bordes y barrios (áreas), que dan lugar a un mapa de síntesis global de la percepción del espacio urbano de Tánger en las novelas españolas del primer quinto del siglo XXI. Un cuarto apartado recoge las consideraciones finales. 


\section{Metodología y fuentes}

\subsection{Metodología}

La investigación analiza la percepción del espacio urbano de Tánger que proyectan las obras contemporáneas de escritores españoles publicadas en el siglo XXI (2002-2019). Se sintetiza la percepción de Tánger de obras de literatos españoles que han tenido como escenario geográfico de sus novelas esta ciudad, muchas de ellas ambientadas en la época en la que estuvo regida por el Estatuto Internacional (1923-1956).

Ejercicio que descubre la percepción urbana de Tánger que se concatena y complementa con otra serie de percepciones que nacen de su condición marítima y encrucijada, de su pasado y presente, donde juega un papel relevante su carácter fronterizo.

Partimos de la hipótesis enunciada por Debarbieux (2015) según la cual existe una tensión constante entre las percepciones heredadas por la historia y trabajadas por la memoria y las percepciones experimentadas en la vida diaria. Esta tensión dinamiza el imaginario individual y colectivo y posee un valor explicativo para muchas prácticas espaciales, particularmente en términos de movilidad y de planificación.

Se ha optado por estudiar la percepción del espacio geográfico de Tánger acotando la fuente a obras literarias de escritores españoles publicadas en el siglo XXI. El campo de estudio de esta investigación es amplio porque desde el inicio del nuevo milenio ha aumentado de forma llamativa el número de novelas ambientadas en Tánger (Rojas-Marcos, 2018). Cuestión que denota la capacidad de atracción de la ciudad, en parte por su estratégico emplazamiento, en parte por su devenir histórico, en parte por su carácter de encrucijada y espacio de contacto de culturas, intereses y sensibilidades diferentes (López Lara, 2008). Esta literatura contemporánea de Tánger se caracteriza "por un interés demostrado en no distorsionar la realidad, sino recrearla, modelarla y repensarla" (Goñi Pérez, 2009, p. 41).

La metodología utilizada se basa en la detección de los elementos urbanos percibidos en las obras en estudio que aparecen relacionadas en la Tabla 1. Atendiendo y adaptando los postulados clásicos de Lynch (1960) que engloba los distintos elementos urbanos que se pueden percibir en una serie de categorías: sendas (como ejes de desplazamiento), hitos (objetos fácilmente identificables por los ciudadanos), nodos (zonas de confluencia), barrios (sectores de la ciudad con identidad) y bordes (rupturas lineales de continuidad-) se han identificado los más percibidos en las novelas en consideración, siguiendo el esquema puesto en uso por Benito y 
Vega (2001) para la ciudad de El Cairo en la trilogía de novelas dedicadas a El Cairo (Entre dos palacios, Palacio del deseo y La Azucarera) de Naguib Mahfuz.

Tabla 1. Elementos geográficos percibidos en el espacio urbano de Tánger

\begin{tabular}{|c|}
\hline SENDAS: ejes de desplazamiento \\
\hline Callejones - Calles - Avenidas - Bulevares \\
\hline NODOS: zonas de confluencia \\
\hline Zoco Chico - Zoco Grande - Miradores \\
\hline HITOS: objetos físicamente identificables \\
\hline $\begin{array}{c}\text { Hospitales - Cementerios - Teatros - Cines - Centros educativos - } \\
\text { Plaza de Toros - Hoteles - Cafés - Estaciones de tren y autobús - } \\
\text { Mezquitas - Iglesias - Sinagogas - Campos deportivos }\end{array}$ \\
\hline BARRIOS: sectores de la ciudad con identidad \\
\hline Medina - Zona de expansión europea - Barrios árabes populares \\
\hline BORDES: rupturas lineales de continuidad \\
\hline
\end{tabular}

Fuente: elaboración propia a partir de Lynch (1960)

A continuación se ha contabilizado el número de veces que estos elementos aparecen en las obras en consideración, lo que da lugar al establecimiento de un orden de relevancia. La detección y aparición de estos elementos geográficos del espacio urbano permite la confección de mapas de la percepción del escenario urbano.

\subsection{Fuentes}

La producción literaria que ha tenido como escenario el territorio de Tánger a lo largo de la historia es amplia y en virtud de su riqueza ha dado lugar a estudios compilatorios. El primero de ellos se debe a González Hidalgo (1993) que es completo y detallado si bien, dada la fecha de su publicación, queda sin reflejar la producción habida entre ambos milenios, es decir, en los últimos veinticinco años, que ha sido notable y abundante. El segundo, recientemente publicado (Rojas-Marcos, 2018), es asimismo pormenorizado y está actualizado, recogiendo todos los autores que escriben en castellano, los propios tangerinos (ya marroquíes, ya españoles) y los españoles no tangerinos que se han acercado y contemplado Tánger en sus obras. Es cierto que un conjunto de literatos procedentes de otros ámbitos geográficos se aposentaron y escribieron en y sobre Tánger, en especial debido a la influencia que ejerció Paul Bowles. 
De la misma manera, se ha de reseñar estudios sectoriales o temáticos, como por ejemplo, sobre las recreaciones literarias de viajeros catalanes en África entre finales del siglo XIX y principios del siglo XX (Garcia Ramon, Nogué \& Zusman, 2008; Cerarols Ramírez, 2015), sobre la literatura de la geografía bélica colonial del norte de Marruecos (Cerarols Ramírez, 2009) o sobre la representación del Protectorado en la novela española (Moga Romero, 2016). Esta completa bibliografía pone en evidencia el interés que Tánger, en los distintos periodos históricos, ha suscitado en la literatura española, en especial, durante la época colonial y del protectorado.

Esta investigación atiende a diez escritores de novelas publicadas en el siglo XXI (entre 2002 y 2019) que tienen a Tánger como escenario geográfico. Aparecen, cronológicamente relacionadas según la fecha de publicación, en la Tabla 2.

Tabla 2. Novelas del siglo XXI (2002-2019) desarrolladas en el espacio urbano de Tánger

\begin{tabular}{|c|c|c|c|}
\hline $\mathrm{N}^{\circ}$ & AUTOR/A & PUBLICACIÓN & TíTULO \\
\hline 1 & Antonio Lozano & 2002 & Harraga \\
\hline 2 & María Dueñas & 2009 & El tiempo entre costuras \\
\hline 3 & Antonio Lozano & 2015 & Un largo sueño en Tánger \\
\hline 4 & Javier Valenzuela & 2015 & Tangerina \\
\hline 5 & Iñaki Martínez & 2016 & La ciudad de la mentira \\
\hline 6 & Arturo Pérez Reverte & 2017 & Eva \\
\hline 7 & Cristina López Barrios & 2017 & Niebla en Tánger \\
\hline 8 & Javier Valenzuela & 2018 & Limones negros \\
\hline 9 & Fernando de Artacho & 2018 & El correo de Tánger \\
\hline 10 & Sergio Barce & 2019 & Malabata \\
\hline
\end{tabular}

Fuente: elaboración propia

Las diez novelas contempladas en la elaboración de esta investigación tienen elementos comunes y diferenciadores. Entre los comunes, como se ha señalado, el uso de un mismo escenario urbano, Tánger, que nace del simpar carácter geoestratégico y de su singular historia desde finales del siglo XIX, aunque destaque con luz propia la época en que estuvo gestionada por el Estatuto Internacional. También algunas novelas desarrollan su trama con mayor contemporaneidad, si bien relacionadas con la segunda parte del siglo XX abarcando los años transcurridos en el siglo XXI.

En todos los casos Tánger no sólo es el soporte urbano donde transcurren los acontecimientos sino que forma parte, siendo protagonista de los hechos o sucesos que se relatan. Los hechos y elementos diferenciadores entre las novelas aludidas han de buscarse en el desarrollo de sus 
respectivos argumentos, donde se contemplan tramas, actores, vivencias y contextos de cada una de ellas.

Siguiendo el discurso cronológico del año de publicación se expone brevemente el argumento de cada novela. Antonio Lozano (desgraciadamente fallecido en el momento en que se escriben estas líneas), con Harraga (2002) publicó una novela que narra de forma descarnada la experiencia del tráfico de drogas y de las mafias y de cómo es vivida y sufrida por tangerinos pertenecientes a las capas sociales humildes a principios de este milenio.

María Dueñas se acerca a la novela negra a través de las andanzas de Sira Quiroga que relaciona sus quehaceres cotidianos con lances de espionaje. Aunque ambienta en Tetuán gran parte del desarrollo de la novela El tiempo entre costuras (2009), Tánger tiene especial presencia en dos fases de la vida de la protagonista. La primera en su llegada a Marruecos, previo paso a la zona del Protectorado de España en Marruecos, en concreto Tetuán, y la segunda, en el desarrollo de la trama detectivesca cuando Sira se desplaza a Tánger por cuestiones que tienen que ver con las aventuras relacionadas con el espionaje en las que se ve envuelta.

Antonio Lozano ofrece un Tánger interiorizado en la novela Un largo sueño en Tánger (2015). No en balde, el escenario urbano se contempla de forma natural mezclado con la propia trama de la novela y con las experiencias vitales del autor tangerino. De hecho, la novela no se adscribe en la categoría de novela negra, de acción o detectivesca. Lozano confecciona una novela en torno a un accidente que sufre la protagonista, Isabel, que le lleva a realizar un fresco excepcional de las vivencias de los españoles tangerinos tras la finalización del periodo del Estatuto Internacional y su búsqueda de nuevas expectativas vitales lejos de Tánger.

Javier Valenzuela publicó la novela Tangerina (2015) protagonizada por Sepúlveda, en la ficción profesor del Instituto Cervantes de Tánger, que fue inaugurado en el año 1993. La novela posee dos tramas separadas cronológicamente por aproximadamente cuarenta años. En cada de ellas las descripciones permiten que la ciudad muestre su esencia a pesar de los cambios que acontecieron entre el periodo en el que fue ciudad internacional hasta los primeros años del presente siglo.

Iñaki Martínez escribió una novela negra y de aventuras ambientada en la ciudad de Tánger publicada en el año 2016 donde destaca el papel jugado por la ciudad en época de entreguerras, cuando fue nido de espía y de intereses estratégicos de distintas potencias, interesadas en el dominio del Estrecho de Gibraltar. La figura del protagonista, el cura vasco Martín Ugarte, y una trama detectivesca que articula estrategias de control del Estrecho de varios 
países (Alemania, Francia, Inglaterra, Estados Unidos, España) construye una novela de intriga en La ciudad de la mentira, cuyo título se inspira en un personaje de una novela de Paul Bowles.

Arturo Pérez Reverte sitúa en Tánger de finales de los años 30 del siglo XX, gran parte de la segunda entrega, llamada Eva (2017), de la serie de libros que protagoniza el desaprensivo detective Lorenzo Falcó, en relación al atraque de un buque con cargamento de oro procedente de la República con destino incierto y que es objeto de la trama que construye y sustenta la novela.

Cristina López Barrios escribe la novela Niebla en Tánger, de estructura peculiar, con la que obtuvo el segundo premio Planeta del año 2017, juega con los tiempos, desde la época del Estatuto Internacional a la actual, y por ello reflejando en su evolución el espacio geográfico del Tánger contemporáneo.

Javier Valenzuela vuelve a situar como protagonista a Sepúlveda, profesor del Instituto Cervantes de Tánger, en Limones negros (2018) donde relata un turbio asunto donde que nos presenta la ciudad más reciente, apareciendo aspectos relacionados con intereses económicos de empresarios y políticos españoles en Marruecos (negocio de móviles, resorts, narcotráfico)

Fernando de Artacho publica El correo de Tánger (2018) en la que el protagonista, Reschet, falangista de origen alemán es contratado por el servicio secreto español que le encarga una misión en Tánger de 1940. Bajo falsa identidad como jefe de correos debe recuperar unos documentos robados que podrían provocar la entrada de España en la Guerra Mundial.

Sergio Barce aporta con Malabata (2019) la última de las novelas que refleja este estudio. El argumento pivota en torno a una investigación llevada a cabo por el protagonista, el inspector marroquí Amin Hourami. Se trata de una novela negra de traidores y espías que refleja el ambiente nocturno y de los cafetines tangerinos.

\section{Análisis geográfico de los elementos urbanos percibidos de Tánger en la literatura española del siglo XXI}

Las obras señaladas coinciden en el uso de un espacio urbano de Tánger acotado donde se desarrolla gran parte de los acontecimientos narrados en los siguientes límites:

- Al norte y noreste, la necrópolis fenicia y el puerto; éste representa además un elemento identificable como parte emblemática de la ciudad, puerta de entrada y salida y nodo de confluencia no sólo de personas, sino de tráfico de mercancías, informaciones e ideas. 
- Al este, hacia levante, ejerce de límite la playa, en concreto, la Bahía de Tánger, desde el puerto hasta Cabo Malabata, borde visible del escenario urbano.

- Difusos se presentan los límites interiores meridional y occidental percibidos, con un trazado noreste - sureste, cuyos vértices serían: Café Hafa, Catedral, Mezquita de Mohamed V, Calle México, Plaza de Francia, Bulevar Pasteur, Plaza de las Naciones hasta la playa.

Este escenario no es baladí al contener la mayor parte de los elementos geográficos percibidos del espacio urbano de Tánger en las novelas en estudio, allí donde desarrollan gran parte de sus respectivas tramas. Por otra parte, se corresponde con los límites urbanos vividos por la comunidad española e internacional en tiempos del Estatuto, tal y como reseña Lozano (2015) cuando relata las vivencias de los españoles que se quedaron allí más tiempo tras la Independencia de Marruecos: "pero supimos definitivamente que ésta (la ciudad) no acababa en los aledaños del bulevar (Pasteur), el Zoco Chico y la Avenida de España" (p. 41)

Los distintos elementos de la percepción del espacio urbano de Tánger durante el periodo que abarcan estas obras (1930-2015), aparecen contabilizados en la Tabla 3.

Las sendas (calles, callejones, avenidas, bulevares) como ejes de desplazamientos son elementos de especial importancia en la percepción de la ciudad ya que señalan rutas de desplazamiento y enlaces, a la vez que representan líneas desde las que se observa la propia ciudad.

En el conjunto de las diez novelas en estudio se ha llegado a cuantificar un total de 200 sendas (Tabla 3), que viene a representar el 16,5 \% de los elementos geográficos detectados. Ello ha permitido obtener la estructura relacional de la percepción urbana de Tánger en la literatura española contemporánea (Figura 2).

Cabe diferenciar las calles de la Medina, frecuentemente aludidas sin nombre como callejuelas, callejas, callejones, etc. salvo excepciones, de las calles de la ciudad moderna europea o extramuros de la Medina. Estas denominaciones no resultan extrañas en tanto en cuanto la percepción de la Medina desde la mentalidad occidental es global, como un todo, indiferenciable en sus zonas o espacios, debido a la peculiar conformación, en apariencia irregular y aleatoria, del urbanismo de las medinas árabes (Navarro \& Jiménez, 2007). 
Tabla 3. Elementos del espacio urbano de Tánger en la literatura española

\begin{tabular}{|c|c|c|c|c|c|c|c|c|c|c|c|c|}
\hline & ESPACIO URBANO & 1 & 2 & 3 & 4 & 5 & 6 & 7 & 8 & 9 & 10 & TOTAL \\
\hline \multirow{10}{*}{ 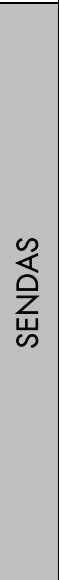 } & BULEVAR PASTEUR & 3 & 3 & 5 & 3 & 11 & 4 & 8 & 8 & 0 & 5 & 50 \\
\hline & CALLE SIAGHINS & 2 & 2 & 1 & 3 & 3 & 6 & 0 & 4 & 1 & 1 & 23 \\
\hline & AVDA ESPAÑA & 3 & 0 & 3 & 1 & 1 & 2 & 2 & 2 & 0 & 1 & 15 \\
\hline & $\begin{array}{c}\text { CALLE LIBERTAD / } \\
\text { ESTATUTO }\end{array}$ & 1 & 1 & 2 & 6 & 0 & 0 & 0 & 1 & 0 & 2 & 13 \\
\hline & CALLE MÉXICO & 0 & 0 & 0 & 8 & 0 & 0 & 0 & 5 & 0 & 0 & 13 \\
\hline & CALLE INGLATERRA & 0 & 0 & 0 & 10 & 0 & 0 & 0 & 0 & 0 & 1 & 11 \\
\hline & CALLE FEZ & 5 & 0 & 3 & 0 & 1 & 0 & 0 & 0 & 0 & 1 & 10 \\
\hline & CALLE ITALIA & 0 & 0 & 0 & 6 & 0 & 1 & 0 & 0 & 0 & 0 & 7 \\
\hline & CUESTA DE LA PLAYA & 1 & 1 & 0 & 3 & 0 & 0 & 1 & 0 & 0 & 0 & 6 \\
\hline & OTROS & 3 & 6 & 5 & 5 & 2 & 4 & 7 & 17 & 1 & 2 & 52 \\
\hline \multirow{15}{*}{$\begin{array}{l}\text { o } \\
\text { 至 }\end{array}$} & HOTEL CONTINENTAL & 0 & 6 & 0 & 1 & 10 & 11 & 6 & 0 & 1 & 2 & 37 \\
\hline & CAFÉ CENTRAL & 12 & 1 & 0 & 5 & 1 & 8 & 3 & 1 & 1 & 1 & 33 \\
\hline & INST CERVANTES & 1 & 0 & 2 & 16 & 0 & 2 & 0 & 10 & 0 & 0 & 31 \\
\hline & HOTEL MINZAH & 1 & 2 & 0 & 4 & 5 & 0 & 3 & 3 & 10 & 1 & 29 \\
\hline & CAFÉ DE PARÍS & 0 & 0 & 0 & 10 & 5 & 0 & 7 & 1 & 0 & 1 & 24 \\
\hline & TEATRO CERVANTES & 1 & 1 & 1 & 12 & 6 & 1 & 0 & 1 & 0 & 0 & 23 \\
\hline & CAFÉ FUENTES & 0 & 0 & 0 & 0 & 0 & 1 & 5 & 12 & 2 & 1 & 21 \\
\hline & CEMENTERIO BUBANA & 0 & 0 & 2 & 0 & 7 & 2 & 0 & 2 & 0 & 0 & 13 \\
\hline & LIBRERÍA COLONNES & 0 & 0 & 1 & 8 & 0 & 0 & 0 & 4 & 0 & 0 & 13 \\
\hline & HOTEL FUENTES & 0 & 0 & 2 & 4 & 1 & 0 & 0 & 3 & 0 & 2 & 12 \\
\hline & GRUPO ESCOLAR & 0 & 0 & 0 & 0 & 11 & 0 & 0 & 0 & 0 & 0 & 11 \\
\hline & MEZQUITA MOHAMED V & 0 & 0 & 0 & 7 & 0 & 0 & 0 & 3 & 0 & 0 & 10 \\
\hline & SINAGOGA NAHÓN & 0 & 0 & 0 & 1 & 5 & 2 & 0 & 0 & 0 & 1 & 9 \\
\hline & CEMENTERIO JUDÍO & 0 & 0 & 0 & 0 & 2 & 4 & 2 & 0 & 0 & 0 & 8 \\
\hline & OTROS & 8 & 9 & 7 & 9 & 6 & 9 & 12 & 15 & 3 & 7 & 85 \\
\hline \multirow{3}{*}{$\begin{array}{l}\frac{o}{\alpha} \\
\frac{o}{\frac{\alpha}{\alpha}} \\
\infty\end{array}$} & MEDINA & 5 & 4 & 3 & 33 & 11 & 37 & 7 & 22 & 2 & 9 & 133 \\
\hline & ENSANCHE EUROPEO & 2 & 3 & 1 & 7 & 1 & 16 & 3 & 23 & 2 & 4 & 62 \\
\hline & BARRIOS ÁRABES & 1 & 1 & 1 & 14 & 5 & 11 & 0 & 12 & 3 & 3 & 51 \\
\hline \multirow{5}{*}{$\begin{array}{l}\text { o } \\
\text { Oิ } \\
\text { z }\end{array}$} & $\mathrm{ZOCO} \mathrm{CHICO}$ & 3 & 2 & 3 & 19 & 15 & 10 & 10 & 7 & 5 & 1 & 75 \\
\hline & ZOCO GRANDE & 0 & 1 & 1 & 18 & 6 & 9 & 1 & 6 & 1 & 3 & 46 \\
\hline & MIRADOR HAFA & 2 & 1 & 1 & 13 & 1 & 0 & 0 & 2 & 0 & 1 & 21 \\
\hline & MIRADOR PEREZOSOS & 1 & 1 & 1 & 2 & 1 & 2 & 0 & 4 & 0 & 1 & 13 \\
\hline & OTROS & 0 & 0 & 0 & 1 & 0 & 2 & 1 & 6 & 3 & 4 & 17 \\
\hline \multirow{4}{*}{ 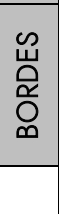 } & PUERTO & 15 & 12 & 3 & 22 & 5 & 21 & 34 & 9 & 9 & 2 & 132 \\
\hline & COSTA - PLAYA & 12 & 0 & 3 & 13 & 6 & 12 & 9 & 15 & 0 & 2 & 72 \\
\hline & MURALLAS MEDINA & 3 & 1 & 0 & 0 & 1 & 10 & 12 & 1 & 0 & 0 & 28 \\
\hline & TOTAL & 85 & 58 & 51 & 264 & 129 & 187 & 133 & 199 & 44 & 59 & 1209 \\
\hline
\end{tabular}

Fuente: elaboración propia 
Dentro de la Medina ha de hacerse una salvedad derivada de la presencia del Zoco Chico, espacio relativamente amplio dentro de ésta, que la divide en dos partes y que queda conectado con el llamado Zoco Grande (antaño, denominado Zoco de las Afueras y hoy, Plaza 9 de abril) a través de la renombrada y bien percibida calle de Siaghins (que aparece escrita de múltiples formas según los distintos autores: Siagins, Siagines, Siaghis...) y con el puerto hacia el sur a través de la Calle Marine. "Desde el Zoco Chico partían las venas por donde circulaba la savia de la ciudad bulliciosa, multicolor, cosmopolita y la calle Siaghins, arteria que aseguraba el tránsito entre dos mundos, conectaba la medina con la ciudad europea" (Lozano, 2015, p. 102).

Figura 2. Sendas y nodos (grafos) del espacio urbano de Tánger

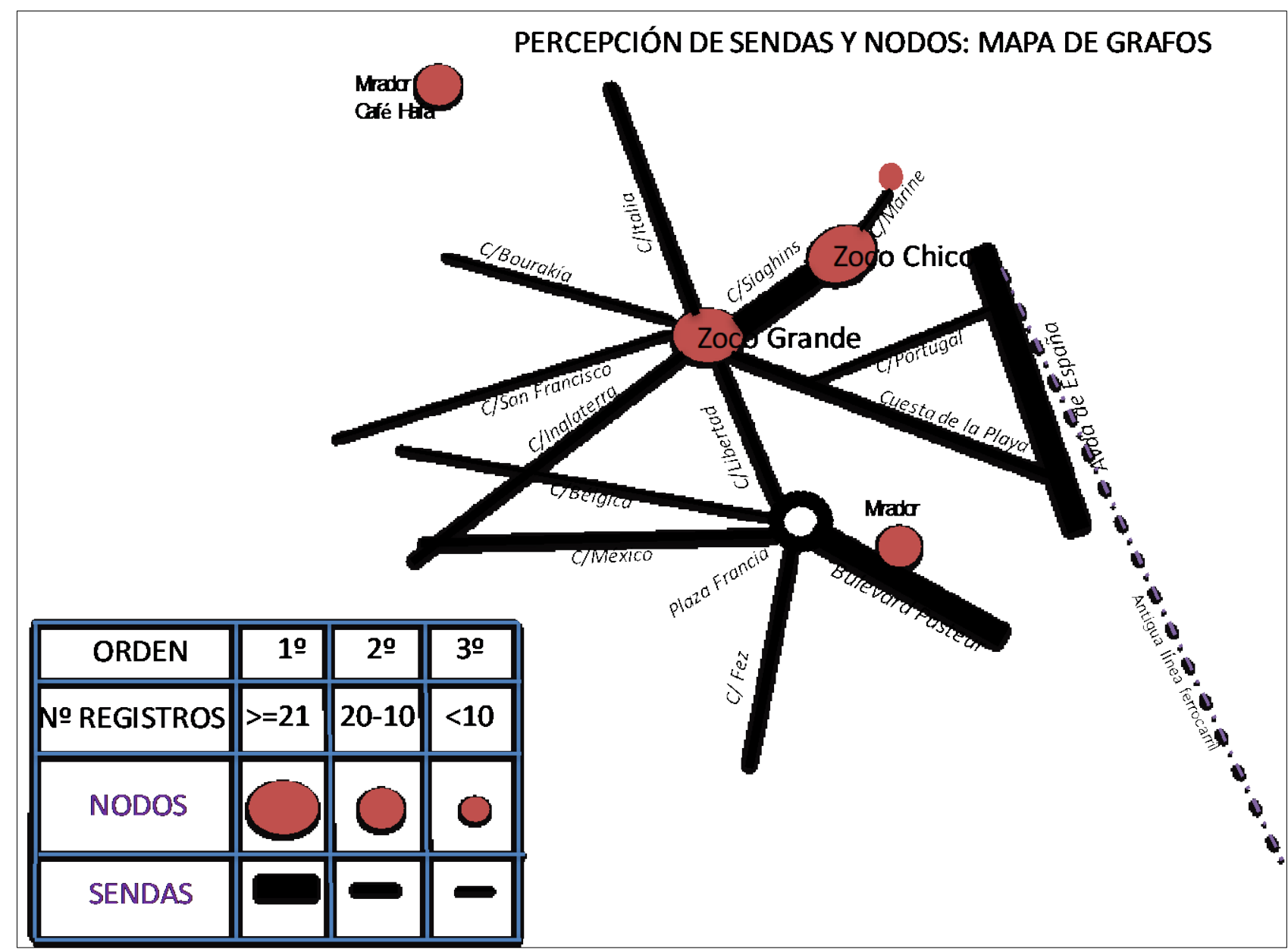

Fuente: elaboración propia

La ciudad europea, primera zona extramuros a occidente de la Medina, zona de crecimiento de finales del siglo XIX y principios del XX, engloba la mayor parte de las sendas percibidas en las novelas de referencia (calles, avenidas, bulevares[), siendo especialmente relevante el Bulevar Pasteur, donde se ubican el Mirador de los Perezosos (con vistas sobre el Estrecho) y el mítico Café de París, en torno a la Plaza de Francia y del Consulado de dicho país. 
El Bulevar queda conectado a través de la Calle Libertad (anteriormente denominada Estatuto) con el Zoco Grande, siendo ambas sendas ampliamente percibidas, conformando el vértice superior de un triángulo que tiene al este, como base, la Avenida de España, que bordea la playa, al sur, la Cuesta de la Playa, en la que en una de sus bifurcaciones en forma de espina de pez se ubica el Teatro Cervantes, y al norte la ya nombrada calle Siaghins.

El Bulevar Pasteur, construido a partir de finales del siglo XIX en una zona de huertas, adquirió relevancia a partir de los años 20 del siglo XX, representando el ensanche de la ciudad diplomática, donde se construyeron edificios de modelo europeo, en especial del estilo internacional francés (Bravo Nieto, 2000).

Este arquitecto señala que la expansión urbana no sólo se realizó con las alineaciones urbanas en torno al Bulevar Pasteur y la Avenida de España, sino también en dirección a

un cinturón urbano que rodeaba totalmente la ciudad antigua y cuyas construcciones se alargaban en torno a las vías radiales que salían del Zoco Grande, multitud de construcciones en la zona de Hasnona y Marxán, edificaciones aisladas en la continuación de estas vías radiales que habían generado zonas como las del barrio de San Francisco. También se imponía sobre unos proyectos urbanos anteriores, como el parcial de alineaciones en la zona de playa y la zona del Boulevard Pasteur y sus aledaños (p. 134).

No es casual que en dirección oeste y sur el desarrollo urbano a partir de la Medina, aparezcan y sean percibidas en las novelas estudiadas las calles que proyectan estos crecimientos de la ciudad, tales como Inglaterra, México, San Francisco, etc. hasta llegar a un límite perceptivo determinado por las confluencias entre el Hospital Español, la Gran Mezquita de Mohamed V, la Catedral y la Iglesia de St. Andrew, al oeste y la Plaza de las Naciones, al sur.

En estas páginas nombramos las calles con la denominación antigua, si bien con la Independencia de Marruecos, en un primer momento (pasada la primera mitad de los años 50), y con la marroquinización (principios de los 70), en un segundo, las calles fueron renombradas, generalmente, con nomenclatura en árabe. De tal forma que las calles Velázquez, Inglaterra, Bélgica, Goya, Juana de Arco, Alejandro Dumas, Pascal, Sevilla, de las Viñas, de los Cristianos, Balmes, Holanda... poseen hoy nuevos nombres en árabe.

Adicionalmente, de forma esporádica, en las novelas estudiadas, encontramos menciones a calles más alejadas, en los "barrios árabes", que se situaban en las zonas periféricas, donde se 
instalaban los suburbios, hoy ya integradas en la ciudad actual, tales como Marchan, Souani, Beni Makada, Casas Baratas, etc.

Los barrios entendidos desde la percepción geográfica como aquellos sectores de la ciudad, no necesariamente correspondientes a unidades administrativas, que presentan cierta identidad y señalando sentido de territorialidad son importantes en Tánger, apareciendo en 246 citas (el $20.3 \%$ de los elementos geográficos considerados).

Destaca, sin lugar a dudas, en la percepción de la ciudad antigua o Medina, ampliamente percibida en las novelas (133 citas), siendo foco de atención y atracción, visible por su singular emplazamiento, en una colina, con bordes naturales (mar) y artificiales (murallas).

La Medina, la ciudad antigua, pese a las transformaciones de finales del siglo XIX y principios del XX debidas a la influencia europea, con la construcción de la Iglesia de la Purísima y numerosas viviendas para diplomáticos y personal europeo, tuvo y sigue detentando el encanto original, que no es otro que el de las medinas árabes, con callejeo zigzagueante y laberíntico, adarves y callejones sin salida y con murallas que la rodean, que facilita sea ámbito referenciado en bastantes lances y pasajes de las novelas, en especial las adscritas al género de novelas negras.

La ciudad europea es identificada con 62 citas, en especial, la que se ciñe a la primera orla en torno a la Medina, circunscrita a las calles Bélgica, México, Bulevar Pasteur al suroeste y la Avenida de España al sureste.

Esta zona de ensanche urbano (finales del siglo XIX y principios del XX) vio ralentizar su crecimiento con la instauración del Estatuto Internacional. No ha de obviarse que, pese a las ventajas que éste supuso en un contexto histórico y geopolítico complejo, también representó, dadas las multiplicidades y las dificultades a la hora de tomar decisiones, una rémora tanto para el crecimiento urbano como para la consolidación de la ciudad como destino turístico (Pack, 2015).

Asimismo, aunque en menor intensidad (65 citas), aparecen los "barrios árabes" de la periferia, hoy ya maclados en la estructura urbana aunque con carencias infraestructurales y sociales notables, tales como Beni Makada, Suani, Casas Baratas, Mesnara, etc. Aparecen en especial en las novelas El año que viene en Tánger, Tangerina, Niebla en Tánger y Limones negros. 
Figura 3. Barrios y límites (áreas) del espacio urbano de Tánger

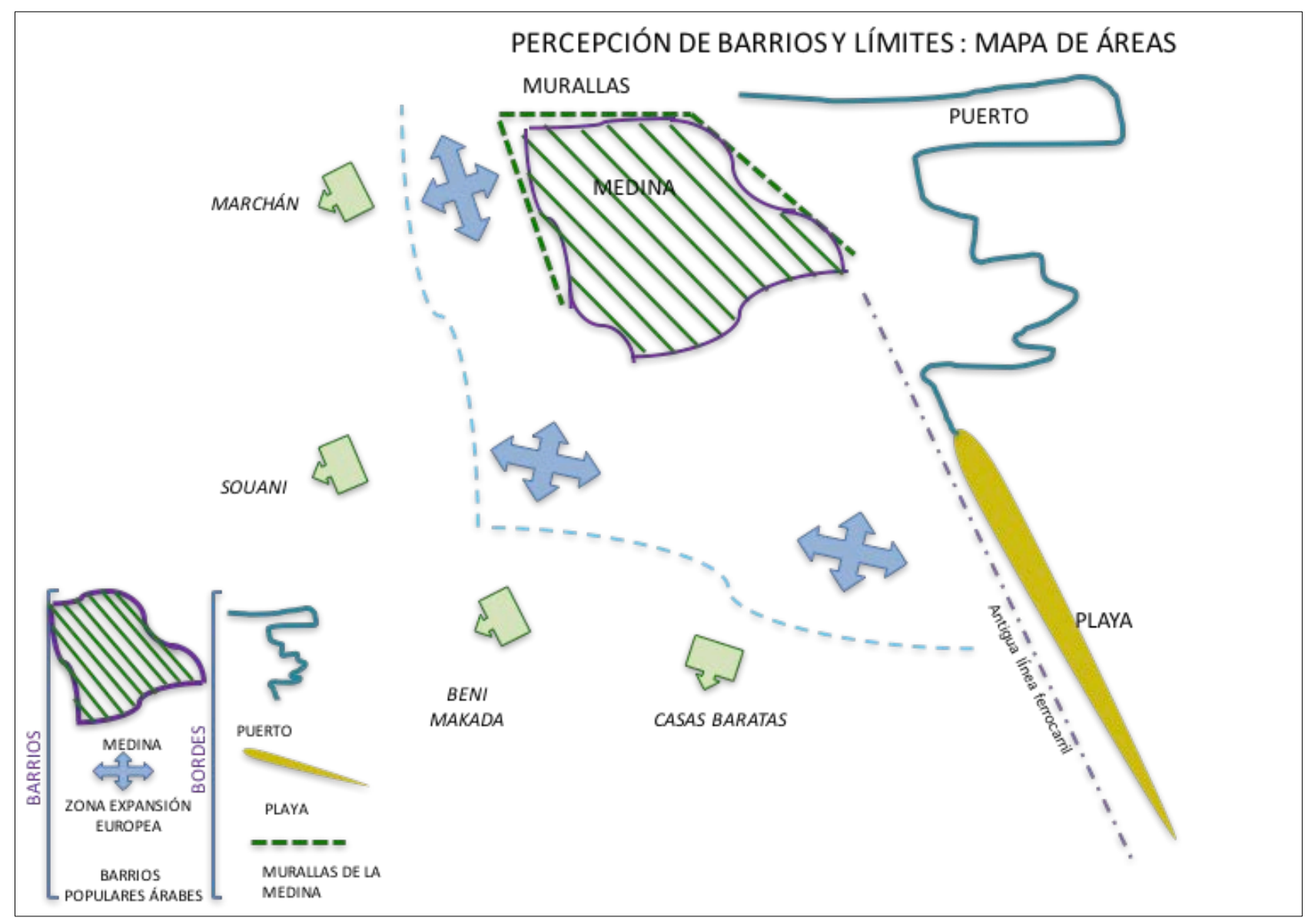

Fuente: elaboración propia

Los bordes o límites, desde la perspectiva de la percepción geográfica, vienen a representar rupturas lineales de continuidad. En las novelas en estudio se han podido detectar 232 citas $(19,2 \%)$ correspondientes con los siguientes bordes: las murallas de la Medina (28), la línea costera (Bahía de Tánger) junto al antiguo tendido ferroviario (72) y el puerto como límite (132). Curiosamente, bordes en el sentido de representar rupturas de linealidades aunque algunos significan nuevas relaciones, conexiones y oportunidades económicas.

El puerto ha sido desde siempre el principal motor de Tánger en cuanto remarca su carácter marítimo, enlaza con el exterior y canaliza los flujos, referenciado en todas las novelas en estudio. El puerto actual está en transformación --tras la puesta en marcha del nuevo puerto Tánger-Med a 40 km de distancia en dirección este hacia Ceuta-- y remodelación, ganándole terrenos a la playa en dirección a la Bahía para construir una nueva terminal para funciones recreativas y deportivas. 
La playa es otro borde por la amplitud de su frente, siendo lugar de enormes potencialidades de disfrute y ocio. Estuvo, la playa, desde la década de los años 30 del siglo XX, reforzada en su carácter de límite o borde con la construcción del tendido ferroviario que se eliminó en la década de los años 80 con la puesta en escena de la nueva terminal en la parte sureste de la ciudad, que dio paso a una inmejorable opción de renovar los amplios espacios del puerto, sumándolos a la ciudad.

Los nodos o nudos, desde la percepción se catalogan como zonas de confluencia de flujos, superficies o lugares estratégicos, siendo en Tánger de especial incidencia en las obras los zocos (como ágoras públicas) y los miradores del Estrecho (como lugares de solaz y ocio), contando 172 citas, el 14.3 \% de los elementos geográficos considerados en el estudio.

El Zoco Chico es, con 75 citas, el núcleo más sensible de la ciudad, el elemento urbano más nombrado en el conjunto de las obras que sirven de fuente a este estudio, espacio público situado dentro de la propia Medina. En él se vieron reflejados momentos esterales de la vida pública de la ciudad en el siglo XX, el lugar de mayor predicamento en su pasado diplomático, donde tuvieron lugar intrigas y compromisos, donde se concentraban consulados y misiones. Por ello, el nodo privilegiado en las distintas novelas, siendo destacado en todas y cada una de las novelas, y, por ello, el más referenciado.

El Zoco Grande (46 citas), localizado entre dos de las puertas de la Medina y conectado con el Zoco Chico por la Calle Siaghins, es una amplia plaza (denominada en origen Zoco de las Afueras), lugar de intercambios donde se encontraban lugareños, turistas y comerciantes. Fue antiguo mercado rural, hoy denominada llamada Plaza 9 de Abril y centro neurálgico de la ciudad. Es reseñable el mercado cubierto junto a las pequeñas tiendas situadas en las inmediaciones del Zoco Chico y del Zoco Grande, en la confluencia con la Cuesta de la Playa, donde se exponen y venden carnes y pescados, frutas y hortalizas, aceitunas y especias, hierbabuena y flores, etc.

El alminar de la mezquita de Sidi Bou Abib da altura al Zoco Grande, junto al Jardín de la Mendubia (al norte) y la iglesia de Saint Andrew (subiendo por la Calle de Inglaterra). Todas las novelas desarrollan parte de sus relatos en este nodo de relación estratégico.

También se deben considerar los miradores, desde los que se contemplan la Bahía de Tánger, el Estrecho de Gibraltar y, en los días claros, las tierras españolas, como nodos ya que son foco de atracción, lugar de paseos y citas. A la par desde ellos se obtiene la vista del horizonte, 
destacando el Mirador de los Perezosos (en el Bulevar Pasteur), el Mirador del Café Hafa (al norte) y el de la Medina, al lado de la Mezquita Mayor, en la parte nororiental.

Figura 4. Hitos y nodos (puntos) del espacio urbano de Tánger

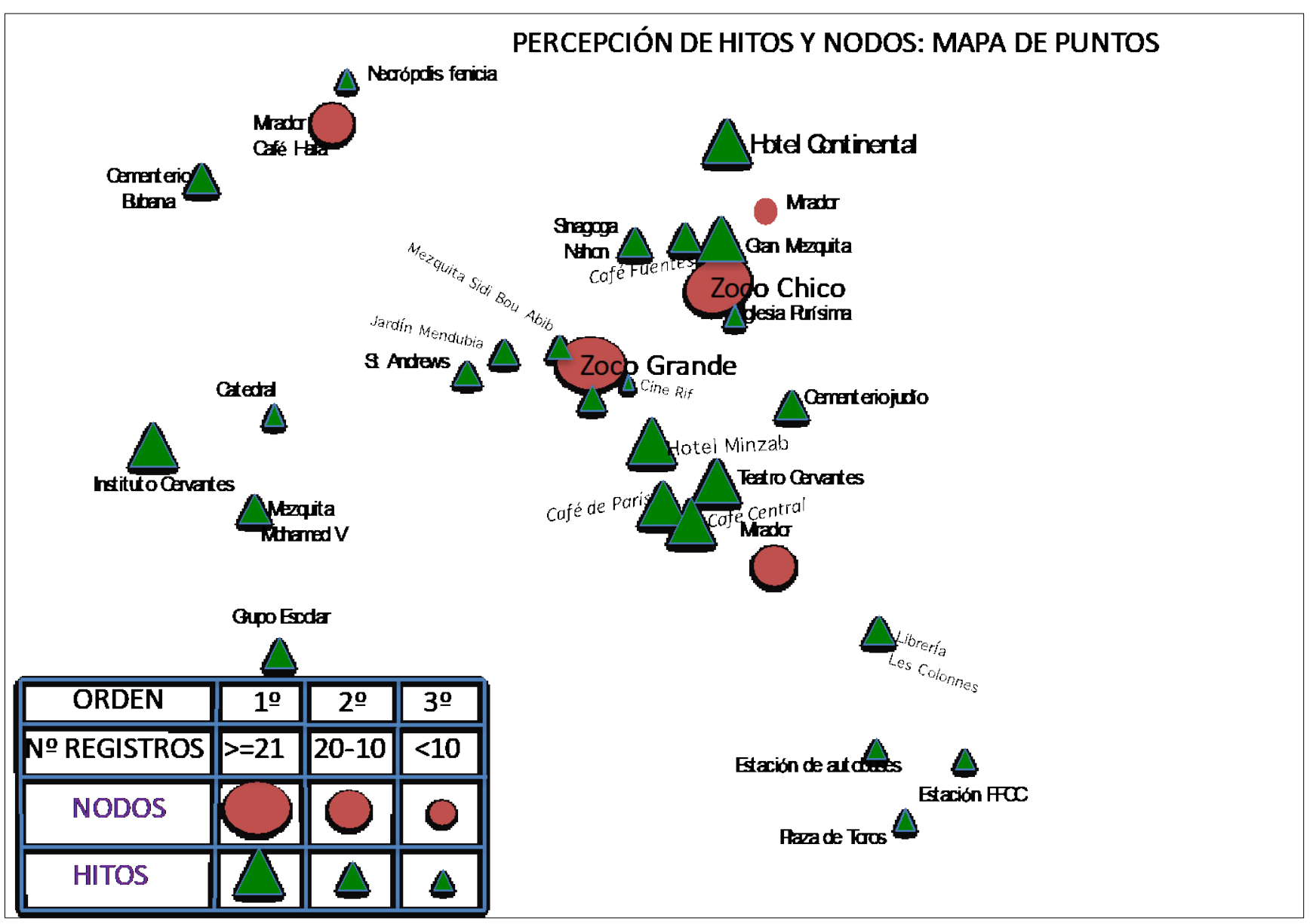

Fuente: elaboración propia

Los hitos urbanos, entendidos como objetos físicamente identificables, significan uno de los elementos más perceptibles en las novelas en análisis, anotándose un total de 359 (29,7\% de los elementos considerados). Representan referencias puntuales, tales como establecimientos de diferentes servicios, tales como de restauración (hoteles, cafés, restaurantes, etc.), culturales (teatros, librerías, institutos, etc.), religiosos (mezquitas, iglesias, sinagogas, cementerios, etc.), etc.

Destacan los hoteles, que en una ciudad como Tánger jugaron -y juegan ahora, dada la vocación turística y la relevancia de los negocios- un papel de especial importancia. El más reseñado y por ello perceptible, es el mítico Hotel Continental (37 referencias), construido a finales del siglo XIX y ubicado en la Calle Dar Baroud, en la parte oriental de la Medina. con vistas al puerto y al Estrecho. 
Cercano en cuanto a su presencia en las obras en estudio aparece el también mítico Hotel El Minzab (29 citas), en la calle de la Libertad (antigua calle del Estatuto), localizado en pleno centro, construido en 1928, frente al Consulado de Francia, en la frontera entre el Zoco Grande y la ciudad nueva o moderna. Sólo deja de aparecer en las novelas Niebla en Tánger y El tiempo entre costuras.

Aparecen, ya en segundo (Hotel Fuentes) y en tercer orden (Hoteles Ville de la France, Cécil, Grand Place, Palmarium, Ville Josephine, Majestic, etc.) que hoy o están cerrados o restaurados, siendo otros los que han venido a sustituirlos, frecuentemente situados o bien en la playa o bien en la parte de ciudad más moderna.

Otros hitos de especial referencia por su percepción son los edificios dedicados al culto, múltiples en Tánger, existiendo iglesias católicas y anglicana, mezquitas y sinagogas, producto de un pasado, en especial la época del Estatuto Internacional, en donde convivían personas que profesaban distintas religiones.

Entre las católicas aparecen la Iglesia de la Purísima Concepción (3 citas), construida en la Medina en 1880-1881, única iglesia que tuvo culto en el interior de una medina árabe "templo que fue hasta la construcción de la catedral el principal edificio religioso católico de la ciudad y su torre un hito visual permanente de su estructura urbana antigua" (Bravo Nieto, 2000) y la Iglesia Catedral, construida entre 1953 y 1961, citada 7 veces en total en las dos novelas de Valenzuela y López Barrios, las más contemporáneas en las fechas de sus relatos.

Entre las sinagogas destacan las de Nahon (9 veces, situada en la Medina, cerca del Zoco Chico) y Chaar Raphaël (2 veces, en el ensanche europeo), reseñadas como parte del crisol cultural del pasado de Tánger. De las mezquitas, la Gran Mezquita en la Medina (5 veces), emplazada en el lugar del antiguo capitolio romano y que fue catedral en época portuguesa, además de la Mezquita de Sidi Bou Abib (4) situada en el Zoco Grande, y de la más reciente y majestuosa, la Mezquita de Mohamed $V(10)$, en la parte occidental moderna ciudad, con impresionante alminar que compite y supera la torre campanario de la Catedral.

Los cementerios son hitos percibidos, tanto el cristiano, llamado Bubana (13), localizado al noroeste de la ciudad, como los judíos, en especial al antiguo hebreo (8) en el entorno de la Medina, en la esquina de las calles Portugal y Cuesta de la Playa, y los musulmanes (especialmente, el antiguo donde hoy se ubican los Jardines de la Mendoubia (4), al igual que la necrópolis fenicia al norte de la Medina (3). De forma esporádica, también queda reflejada la tumba de Ibn Battuta, en la parte norte del interior de la Medina. 
Figura 5. Elementos geográficos del espacio urbano de Tánger

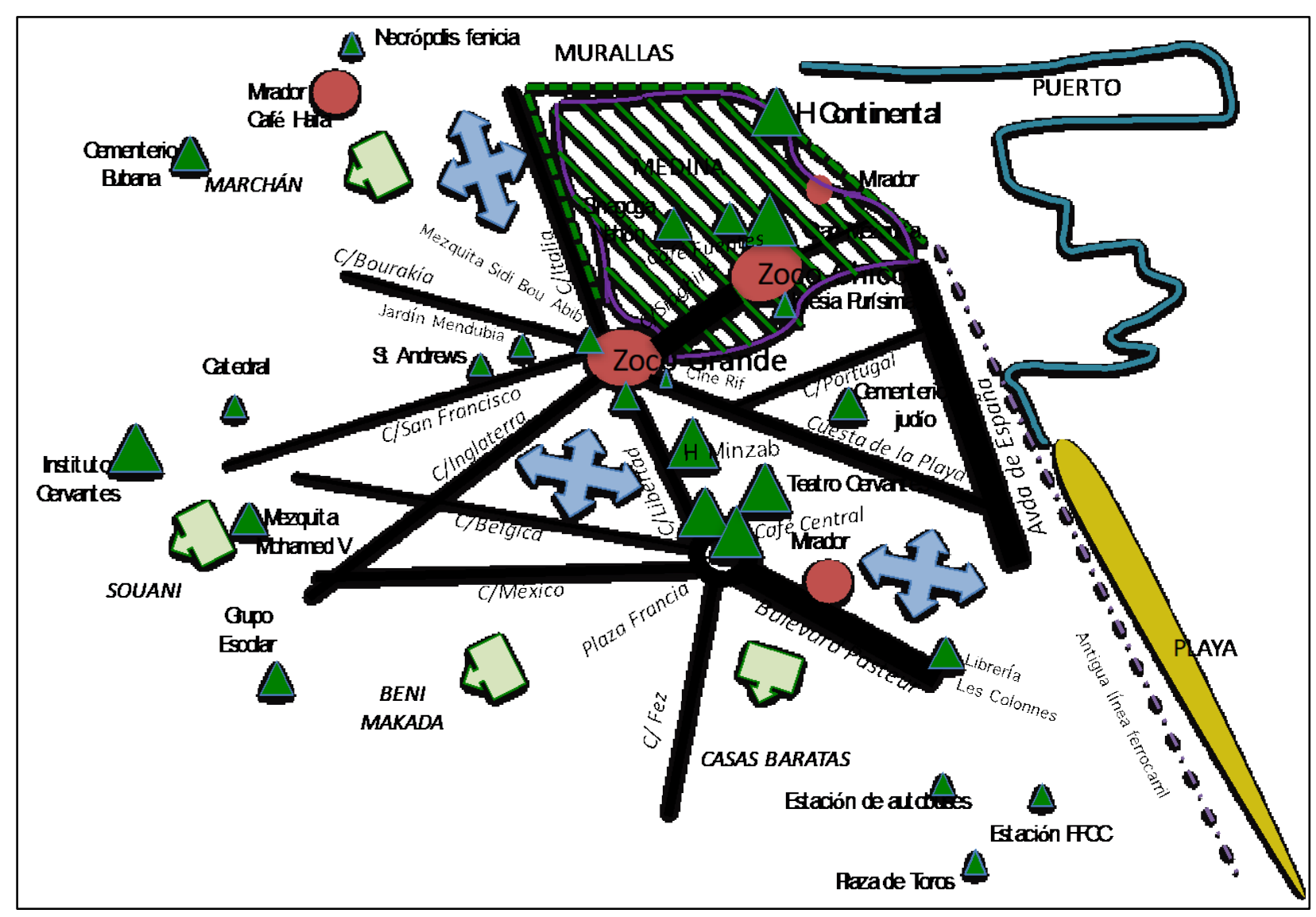

LEYENDA

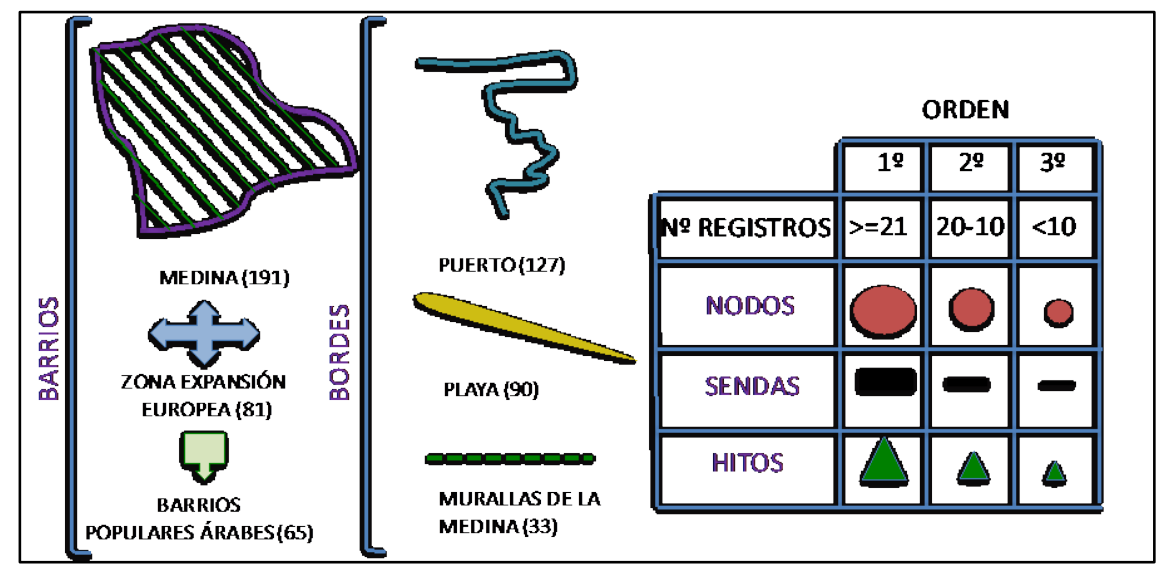

Fuente: elaboración propia

Elementos singulares como hitos de la presencia española fueron el Teatro Cervantes y la Plaza de Toros. El Teatro Cervantes, con un total de 23 referencias, se ubica cerca de la Medina, representa el edificio modernista más importante de la ciudad, símbolo de una determinada forma de sentir la ciudad (Bravo Nieto, 2000). La Plaza de Toros, única permanente en el escenario marroquí, aparece reseñada 4 veces en Un largo sueño en Tánger y en Limones negros, ya en su función actual de lugar de acogida de la población inmigrante subsahariana. En 
esta última obra de Javier Valenzuela, junto a su obra anterior, Tangerina, aparece notablemente visibilizado el Instituto de Cervantes de Tánger, de más reciente creación, en el año 1993.

Elementos e hitos perceptibles culturales en las novelas en estudio son los cines, que abundaron, tales como Kursaal, Capitol, Rif, Mauritania, etc. De relevancia han resultado los lugares de ocio y restauración, con luz propia los cafés (tradicionales desde la época del Estatuto, en especial los del Zoco Chico y Bulevar París, tales como el Café Central (33), el Gran Café de París (24), el Café Fuentes (21) y otros puntuales tales como Tingis, o el Café Hafa, que ejerce también de mirador, además de las reseñas de restaurantes tales como Pagode, Dorado, etc.

Asimismo, ha de hacerse mención, como hitos mencionados, a los hospitales, que en el caso de Tánger abundaron: Hospital español, francés, inglés e italiano más los recientes marroquíes. Por último, aunque en menor número de citas, aparecen los museos.

Caso especial, requiere el tratamiento de la Librería De Les Colonnes, hito situado en el Bulevar Pasteur, mencionada un total de 18 veces, en especial en la novela Niebla en Tánger, y en las obras de Valenzuela, en todos los casos como elemento articulador de la vida cultural de Tánger.

\section{Consideraciones finales}

Los elementos geográficos del espacio urbano de Tánger percibidos en la literatura española contemporánea del siglo XXI y su plasmación cartográfica, aparte de informar de la percepción geográfica común de los autores estudiados, abren una vía para su puesta en valor como recurso cultural.

Las sendas más referenciadas son, en orden de importancia: Bulevar Pasteur, Calle Siaghins, Avenida de España, Calle Libertad o del Estatuto, Cuesta de la Playa, Calle Fez, Calle Inglaterra, Calle Italia, Calle México, Avenida de San Francisco, Calle Bélgica, etc. sin olvidar las calles, callejas o callejones zigzagueantes y laberínticos de la Medina.

El grafo conformado por el eje Bulevar Pasteur - Plaza de Francia - Calle de la Libertad - Zoco Grande - Calle de Siaghins - Zoco Chico - Avenida de España es el que dibuja la percepción, junto al haz de calles que en dirección norte (Calle Italia), sur (Cuesta de la Playa - Calle Portugal) y oeste (Calle San Francisco - Calle Bélgica - Calle México) pivotan desde el Zoco Grande.

Los hitos que más han sobresalido se aglutinan en la Medina o en su entorno próximo. Son los Hoteles Continental y Minzab, los cementerios judío, cristiano y musulmán, la lglesia de la 
Purísima, la Gran Mezquita y la Mezquita de Sidi Bou Abib, el Teatro Cervantes, los cines Mauritania, Rif y Capitolio, los Cafés Central, París, Fuentes y la Librería De Les Colonnes. Asimismo, fuera de la Medina aparecen algunos hitos tales como la Mezquita de Mohamed $V$, la Catedral, la Iglesia de St. Andrew. Los barrios más perceptibles son la Medina y el ensanche de la zona europea hacia oeste y sur de la propia Medina.

Los nodos o nudos, como tales, sirven de articulación entre ejes e hitos, siendo en Tánger dos los que sobresalen con luz propia, el Zoco Chico, en plena Medina, y el Zoco Grande, en una de sus puertas de acceso, viniendo a representar ejemplos palmarios que reflejan la percepción que, desde las obras literarias, se obtiene. Además de los Miradores de los Perezosos y el de la Medina además del Mirador que representa el Café Hafa.

Finalmente, los bordes, como tales límites, son en Tánger nítidos y acotan norte y este de la ciudad: el puerto y el frente marítimo, tanto al norte (necrópolis fenicia) como al este (la playa de Bahía de Tánger).

Tánger goza de cualidades y caracteres que la convierten en ciudad con capacidad de atracción. No en balde son múltiples y variados, frecuentemente complementarios, los calificativos que recibe Tánger como ciudad: única, irrepetible, milenaria, blanca, de la luz, del sueño, entre dos mares, de la mentira, de la traición, mestiza, de la corrupción, refugio, etc. Calificativos que son reflejo de su historia y de su carácter fronterizo, geográfico y cultural, siempre latente y a caballo de dos realidades: la que produce la riqueza de la convivencia y la que decanta el abismo del enfrentamiento.

Confluencias y contrastes que dieron y dan lugar a un desarrollo cultural intenso y a la conformación de una ciudad plena de posibilidades culturales. Un ciudad que guarda un rico patrimonio, tangible e intangible. Estas peculiaridades y caracteres dibuja un ámbito social, económico y territorial con muchas posibilidades para el desarrollo de tramas y argumentos de novelas y películas.

Son bastantes las novelas que han encontrado acomodo en este ámbito geográfico y cultural, especialmente en las dos últimas décadas, coincidiendo los años transcurridos del milenio. Unido a ello, Tánger destaca como escenario de series televisivas, algunas derivadas de las propias novelas, como El tiempo entre costuras y otras no, como en el caso de la serie Cuéntame y de distintas películas, generalmente de acción e intriga, como las de las series de James Bond (Spectre) y de Bourne (El ultimátum de Bourne), o en la película derivada de la famosa novela de Ángel Vázquez, La vida perra de Juanita Narboni. 
No sólo vive Tánger del pasado o de su leyenda ya que las tramas de las novelas en análisis indican nuevas y actuales perspectivas basadas en sus realidades contemporáneas: drama actual de la inmigración, fundamentalismo terrorista y permisividad sexual pasando por detectives, espías, estrategias y juegos de intereses de varios países con conflictos abiertos hasta actualidad de los temas del narcotráfico, del blanqueo del dinero y de la corrupción.

La obras literarias en estudio reflejan un territorio frontera no sólo desde la perspectiva geográfica, sino también cultural, donde la permisividad y relajación de normas no está reñida con la imagen de un país de profundas raíces culturales en el islam.

En este sentido las percepciones de Tánger y de Marruecos desde distintas perspectivas, como es el caso de los canales turísticos, de los medios de comunicación y otras fuentes históricoartísticas (Martín Corrales, 2002) no suelen coincidir y obedecen, generalmente, a objetivos y fines determinados. De esta manera, la percepción turística de Marruecos proporcionada en internet aparece sesgada hacia aspectos positivos, estereotipada al destacar todo aquello que sea de atracción al turista occidental, una reinterpretación del orientalismo (Said, 1990) al servicio del mercado turístico (López Lara, 2005). Se omiten otros que no lo son y que, por lo general, se vuelven invisibles.

En cambio, las percepciones que reflejan los medios de comunicación, oscilan en relación a lo que informe, ofreciendo generalmente un estado de la cuestión no sólo de Tánger, sino de Marruecos y del mundo árabe-islámico, en general, escasamente positiva, incidiendo en el choque cultural y religioso, en la inmigración ilegal, en el integrismo, en el contrabando, en el blanqueo de dinero y el tráfico de drogas (Serna, 2006).

Tánger posee por ubicación geográfica, condiciones naturales, desarrollo histórico, patrimonio artístico-cultural y carácter fronterizo un atractivo que es aprovechado desde la vertiente turística tanto en la época de la Zona Internacional (Araque Jiménez, 2015) como en la actualidad, cuestión que se deja notar en sus recursos, infraestructuras y estadísticas turísticas (López Sánchez \& Arcila, 2014).

Como propuesta tras el estudio realizado concluimos que resultan necesarios estudios que tracen rutas y recorridos literarios, con apego al terreno, que fomenten y hagan atractivo el viaje cultural que se encuentre relacionado con el hecho turístico. Las rutas literarias representa una práctica turística que se asocia al patrimonio, que se enlaza con los lugares y las tramas de los autores, que relaciona la ficción con el mundo real (Morère Molinero, 2012). Se hace necesario ahondar 
y hallar canales para potenciar este recurso desde la perspectiva turística. De esta forma, podría diversificarse la oferta con el fin de poder captar turismo de mayor cualificación.

Tánger se revela como escenario infinito al poseer otra cualidad que resulta principal, que no es otra que la virtud de adaptarse y, por ello, de renovarse, a las nuevas tendencias y realidades nacidas al calor de su estratégico emplazamiento geográfico. Emplazamiento que en el siglo XXI deriva en temáticas relacionadas con el narcotráfico, con el blanqueo de dinero, con el islamismo, con las bondades de la convivencia de culturas, con las incidencias de la emigración irregular, con las nuevas significaciones y realidades de las fronteras contemporáneas.

Declaración responsable: Las/os autoras/es declaran que no existe ningún conflicto de interés con relación a la publicación de este artículo 


\section{Bibliografía}

Araque Jiménez, E. (2015) Orígenes y desarrollo del turismo en el protectorado español del norte de Marruecos (1912-1956). Cuadernos de Turismo, 36, 5577. http://dx.doi.org/10.6018/turismo.36.230881

Artacho, F. (2018). El correo de Tánger. Sevilla: Algaida.

Barce, S. (2019). Malabata. Málaga: Genal.

Benito Arranz, J., \& Vega Benayas, S. (2000). La percepción geográfica de El Cairo de la Trilogía de Naguib Mahfuz. Philologia hispalensis, 14(2), 93-104. Universidad de Sevilla. Retrieved from http://institucional.us.es/revistas/philologia/14_2/art_10.pdf

Boira Maiques, J. V. (2012). Literatura y geografía se dan la mano. A propósito de la novela El mapa y el territorio. Biblio 3W, XVII(995). Retrieved from http://www.ub.es/geocrit/b3w995.htm.

Bravo Nieto, A. (2000). Arquitectura y Urbanismo Español en el Norte de Marruecos. Sevilla: Consejería de Obras Públicas y Transportes. Junta de Andalucía. Retrieved from http://espacio.uned.es/fez/view/bibliuned:UNEDCentroAsociadoMelilla-Libros-7005

Catalá Marticella, R. (2017). La geografía com a narració descriptiva i com construcció d’una "pedagogía del món". La literatura paisajística de Josep Pla com a cas d'estudi" (Doctoral dissertation, Universitat de Barcelona, Spain). Retrieved from https://www.tesisenred.net/handle/10803/562674\#page=1

Ceballos, L. (2006). Historia de Tánger. Córdoba: Almuzara.

Cerarols Ramírez, R. (2009). Paisaje y memoria. Recreaciones literarias de la geografía bélica colonial en Marruecos. Boletín de la Asociación de Geógrafos Españoles, 51, 219-248. Retrieved from https://www.age-geografia.es/ojs/index.php/bage/article/view/1139/1062

Cerarols Ramírez, R. (2015). Geografías de lo exótico: El imaginario de Marruecos en la literatura de viajes (1859-1936). Barcelona: Ediciones bellaterra.

Debarbieux, B. (2015). L'espàce de l'imaginaire. Essais et détours. Paris: Éditions du Centre National de la Recherche Scientifique (CRNS).

Desbois, H. (2002). Réflexions à partir de l'experience du séminaire "Territories littéraires". In J. Bessièrre, Savoirs et littérature: Literature, the humanities and the social sciences (pp. 65-74). Paris: Presses Sorbonne Nouvelle. 
Dueñas, M. (2009). El tiempo entre costuras. Madrid: Temas de Hoy.

González Hidalgo, J. L. (1993). Tánger en la literatura española. Madrid: Instituto de Cooperación con el Mundo Árabe.

Goñi Pérez, J.M. (2009). Los mundos imaginarios postcoloniales. Aljamía, 20, 41-49.

Lévy, B. (2006). Geografía y literatura. In D. Hiernaux \& A. Lindon (Dirs.), Tratado de Geografía Humana (pp. 460-480). Barcelona: Anthropos, UAM.

López Barrios, C. (2017). Niebla en Tánger. Madrid: Planeta.

López Lara, E. (2005). Imagen turística de Marruecos en Internet. Reinterpretando el Orientalismo. Cuadernos de Turismo, 16, 123-134. Retrieved from https://revistas.um.es/turismo/article/view/18371

López Lara, E. (2008). El espacio fronterizo del norte de Marruecos: alternativas de cooperación y desarrollo. Estudios Fronterizos, 17, 43-71. Retrieved from

http://www.scielo.org.mx/scielo.php?script=sci_arttext\&pid=S0187-69612008000100002

López Sánchez, J.A., \& Arcila, M. (2014). Análisis de la percepción turística en la Región Tánger-Tetuán (Marruecos). Cuadernos de Turismo, 33, 173-198. Retrieved from https://revistas.um.es/turismo/article/view/195701

Lozano, A. (2002). Harraga. Granada: Zoela.

Lozano, A. (2015). Un largo sueño en Tánger. Córdoba: Almuzara.

Lynch, K. (1960). The image of the city. The Massachussets Institute of Tecnology. Cambridge.

Martín Corrales, E. (2002)- La imagen del magrebí en España. Una perspectiva histórica siglos XVI--X. Barcelona: Ed. Bellaterra.

Martínez, I. (2015). La ciudad de la mentira. Colección Ánfora \& Delfín. Ed. Destino.

Moga Romero, V. (2016). El duelo del pied-noir: una reflexión acerca de la representación del Protectorado en la novela española actual. In El Protectorado español en Marruecos: La Historia trascendida (pp. 247-279). Ed. Iberdrola. Retrieved from http://doczz.es/doc/336456/descargar-pdf--la-historia-trascendida

Moretti, E. (2000). Atlas du roman européen (1800-1900). Paris: Editions du Seuil.

Navarro Palazón, J., \& Jiménez Castillo, P. (2007). Algunas reflexiones sobre el urbanismo islámico. Revista Artigrama, 22, 259-298. Retrieved from 
https://www.unizar.es/artigrama/pdf/22/2monografico/09.pdf

Pack, S. (2015). Turismo, urbanismo y colonialismo en Tánger, 1880-1939. Cuadernos de Historia Contemporánea, 37, 45-65. https://doi.org/10.5209/rev_CHCO.2015.v37.50986

Pérez Reverte, A. (2017) Eva. Ed. Planeta.

Pocock, D.C.D. (1988). Geography and literature. Progress in Human Geography, 12(1), 82-102.

Rojas-Marcos, R. (2018). Tánger, Segunda Patria. Una ciudad imprescindible en la historia y la literatura española. Córdoba: Almuzara.

Said, E. W. (1990). Orientalismo. Córdoba: Ed. Libertarias/Prodhufi, S.A.

Sagnes-Alem, N. (2007). Le mythe de Tanger et Ángel Vázquez. Figures de la mythification dans I'Espagne du XXe siècle. Montpellier: Presses universitaires de la Méditerranée. Retrieved from https://books.openedition.org/pulm/632?lang=es

Serna (de la), A. (2006). Al sur de Tarifa. Madrid: Marcial Pons.

Suárez Japón, J.M. (2002). Geografía y literatura en los escritos de viaje de José Manuel Caballero Bonald. Boletín de la Asociación de Geógrafos Españoles, 34, 133-146. Retrieved from https://bage.age-geografia.es/ojs/index.php/bage/article/view/432

Tuan, Yi-Fu (1978). Literature and geography: implications for geographical research. In D. Ley \& M. Samuels (Eds), Humanistic Geography: Prospects and Problems. London: Croom Helm, 194206.

Valenzuela, J. (2015). Tangerina. Barcelona: Martínez Roca.

Valenzuela, J. (2016). Limones negros. Sevilla: Anantes.

Valle Buenestado, B. (2015). Geografías literarias, paisajes sin cartografías. In Análisis espacial y representación geográfica: innovación y aplicación (pp. 1261-1270). Universidad de Zaragoza y Asociación Geógrafos de España. Retrieved from http://congresoage.unizar.es/eBook/trabajos/132_Valle\%20Buenestado.pdf

V.AA. (2016). El Protectorado español en Marruecos: La Historia trascendida. Madrid: Iberdrola. Retrieved from http://doczz.es/doc/336456/descargar-pdf-la-historia-trascendida 